\title{
Hygrothermal performance of innovative renovation renders used for different types of historical masonry
}

\author{
J. Kočí ${ }^{1}$, J. Maděra ${ }^{1}$, P. Rovnaníková ${ }^{2} \&$ R. Černý ${ }^{1}$ \\ ${ }^{1}$ Department of Materials Engineering and Chemistry, \\ Faculty of Civil Engineering, Czech Technical University in Prague, \\ Czech Republic \\ ${ }^{2}$ Institute of Chemistry, Faculty of Civil Engineering, \\ Brno University of Technology, Czech Republic
}

\begin{abstract}
A combined experimental-computational approach is applied for the estimation of service life of innovative renovation renders. In the experimental part, the durability of two commercial renovation renders is determined in terms of their frost resistance, together with two newly developed renovation plasters that are supposed to be produced commercially in the near future. The computational part is aimed at the investigation of freeze-thaw cycles that may occur in surface layers of the plaster during its life time period. To achieve this, a diffusion type model of coupled heat and moisture transport is used. As a load-bearing structure several materials which are characteristic for historical buildings are chosen, namely ceramic brick, sandstone and arenaceous marl.
\end{abstract}

Keywords: service life estimate, renovation renders, heat and moisture transport, experimental analysis, frost resistance.

\section{Introduction}

In the current practice of historical buildings renovation, the service life of new surface layers is estimated mostly on the basis of experience, because too few parameters are known for reliable durability estimate. Usually the durability is given by the producer of the renovation render, which provides a warranty period only in the case that the technological process is followed precisely. The service 
life of new surface layer made of renovation render is usually declared between 10 and 15 years. Unfortunately, the real service life is much lower if we take into account climatic conditions, location of the building, local building environment and last but not least, a material composition. As it has been proven in [1-4] a proper material configuration of building envelope may significantly extend its service life. Combination of improperly chosen materials can lead to damage caused by moisture transport through the interface between materials [5].

In this paper, we apply for the solution of the problem of damage of surface layers of historical buildings, a method which was not frequently used until now. The method consists of a combination of computational and experimental approaches. In the experimental part, durability of several innovative renders developed under laboratory condition on the lime-pozzolana basis is determined in terms of their frost resistance. In the computational part, the number of frost cycles in a real structure is identified using a computational analysis. In addition, the computer code involves the effect of hysteresis of moisture transport and storage parameters, which brings the computations nearer to reality. With knowledge of the yearly number of freeze-thaw cycles in the surface layers we can determine the service life of renovation renders by comparing with laboratory experiments.

Prediction of moisture and temperature fields in the building envelope parts of historical buildings over a sufficiently long time makes it possible not only for a reliable analysis of durability of surface layers on the basis of a sufficient amount of input parameters, but also for a design of the time schedule of repeated repairs. It can also offer to the supervisory authorities alternative solutions of surface layers taking into account their durability and financial demand.

\section{Studied building envelopes}

The studied building envelope is presented in Figure 1. It consisted of a loadbearing structure and single layered renovation plaster on the exterior and interior side.

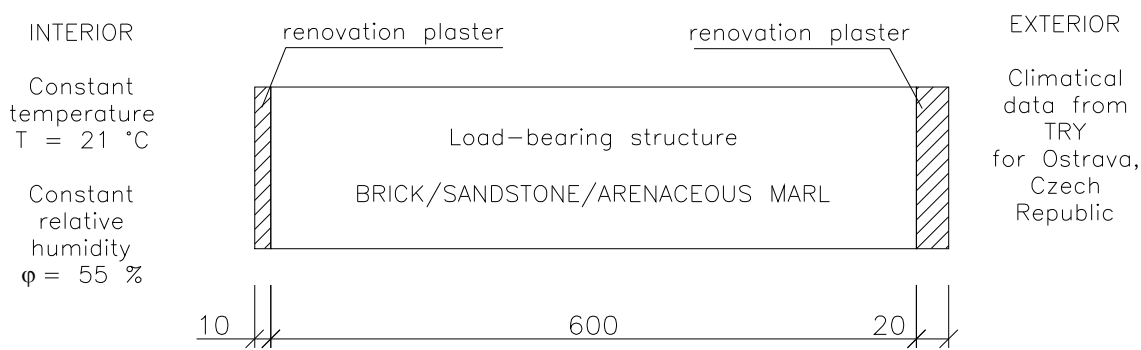

Figure 1: $\quad$ Scheme of studied envelope. 
Three different kinds of materials of load-bearing structure were considered ceramic brick, sandstone and arenaceous marl - together with two commercial renovation plasters $\left(\mathrm{CRP}_{1}\right.$ and $\left.\mathrm{CRP}_{2}\right)$ and two laboratory developed systems of renovation plasters which are supposed to be produced commercially in the near future $\left(\mathrm{LRP}_{1}\right.$ and $\left.\mathrm{LRP}_{2}\right)$.

The thickness of the load-bearing structure was $600 \mathrm{~mm}$ for all materials; the thickness of renovation plaster was $10 \mathrm{~mm}$ for interior side and $20 \mathrm{~mm}$ for exterior side. The investigated point was placed into the exterior plaster, $2 \mathrm{~mm}$ from the exterior surface in order to determine the number of freeze/thaw cycles.

\section{Experimental}

In the experimental work, the frost resistance of the chosen plasters was investigated under laboratory conditions according to ČSN 722452 "Testing of frost resistance of mortar". The specimen had dimensions of 40/40/160 mm. After removal from the moulds they were placed into open boxes and humidified once per day until the end of the 28-days curing period. Temperature in the laboratory was $21 \pm 1^{\circ} \mathrm{C}$, relative humidity was $45 \pm 5 \%$.

In order to measure freeze-thaw resistance of renovation renders, the water saturated testing specimens were cyclically frosted and defrosted until their damage got apparent. Three testing specimens of every plaster were put into water having temperature of $20 \pm 1^{\circ} \mathrm{C}$ until their full saturation. After that, the specimens were removed from water and then they were wiped by paper towel and put into plastic bag. Packed specimens were put into freezing box for at least 4 hours at temperature of $-20 \pm 3{ }^{\circ} \mathrm{C}$. After removal, the specimens were kept in laboratory with temperature of $20 \pm 1^{\circ} \mathrm{C}$ for 2 hours, and then were put into water for 16 hours. This cycle was repeated until the visible damage of specimens. The picture of plasters after 30 freeze-thaw cycles is shown in Figure 2. There is
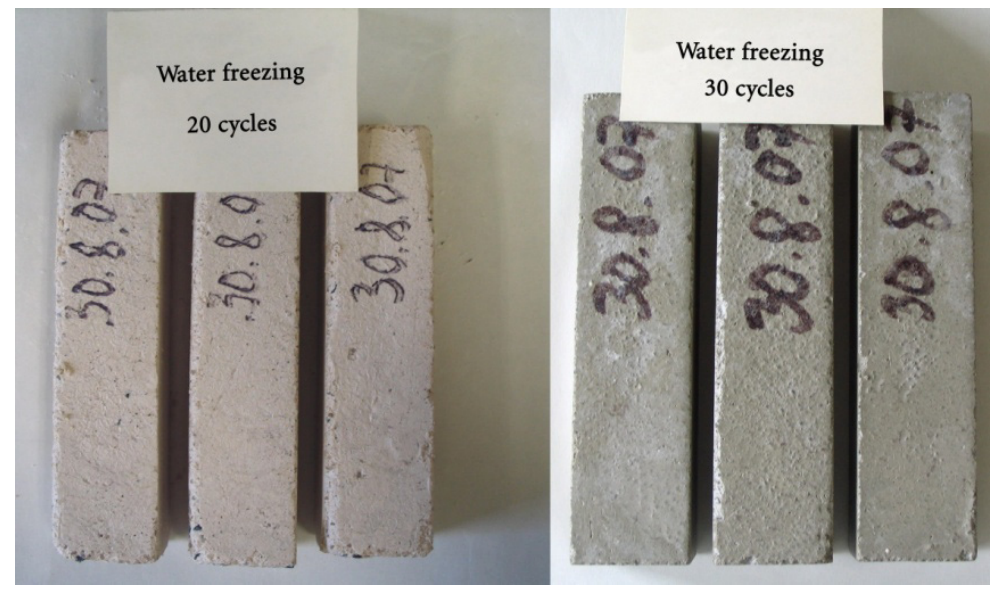

Figure 2: Commercial plasters after $20 / 30$ freeze-thaw cycles $\left(\mathrm{CRP}_{1}\right.$ on the left, $\mathrm{CRP}_{2}$ on the right). 
apparent a little surface destruction of both coats, but the surface still seems to be compact. The overall freeze-thaw durability is shown in Table 1. Commercial plasters (CRP1 and CRP2) after different number of freeze-thaw cycles are shown in Figure 2.

Table 1: Number of freeze-thaw cycles causing apparent damage of renovation renders.

\begin{tabular}{|c|c|c|c|c|}
\hline & $\mathrm{CRP}_{1}$ & $\mathrm{CRP}_{2}$ & $\mathrm{LRP}_{1}$ & $\mathrm{LRP}_{2}$ \\
\hline \hline Number of freeze-thaw cycles & $30+$ & 20 & 15 & 12 \\
\hline
\end{tabular}

\section{Computational}

\subsection{Materials characteristics}

Basic parameters of materials involved in computer simulations are presented in Tables 2 and 3, where $\rho$ is the bulk density, $\psi$ the porosity, $\mu$ the water vapour diffusion resistance factor, $w_{\text {hyg }}$ the hygroscopic moisture content by volume, $c$ the specific heat capacity, $\lambda_{\text {dry }}$ the thermal conductivity in dry conditions, $\lambda_{\text {sat }}$ the thermal conductivity in water saturated conditions.

Table 2: $\quad$ Material parameters of renovation renders.

\begin{tabular}{|c|c|c|c|c|}
\hline & $\mathrm{CRP}_{1}$ & $\mathrm{CRP}_{2}$ & $\mathrm{LRP}_{1}$ & $\mathrm{LRP}_{2}$ \\
\hline \hline$\rho\left[\mathrm{kg} / \mathrm{m}^{3}\right]$ & 1296 & 1384 & 1687 & 1694 \\
\hline$\psi[\%]$ & 50.2 & 47.3 & 34.1 & 34.4 \\
\hline$c_{\text {dry }}[\mathrm{J} / \mathrm{kgK}]$ & 1073 & 1028 & 877 & 877 \\
\hline$c_{\text {sat }}[\mathrm{J} / \mathrm{kgK}]$ & 1545 & 1719 & 1311 & 1311 \\
\hline$\mu_{\text {dry cup }}[-]$ & 23.32 & 12.60 & 29.03 & 31.48 \\
\hline$\mu_{\text {wet cup }}[-]$ & 6.67 & 7.10 & 11.57 & 14.12 \\
\hline$\lambda_{\text {dry }}[\mathrm{W} / \mathrm{mK}]$ & 0.293 & 0.366 & 0.886 & 0.836 \\
\hline$\lambda_{\text {sat }}\left[\mathrm{W} / \mathrm{mK}^{3}\right]$ & 1.383 & 1.186 & 2.190 & 2.267 \\
\hline$w_{\text {hvg }}\left[\mathrm{m} / \mathrm{m}^{3}\right]$ & 0.0932 & 0.0307 & 0.0493 & 0.0437 \\
\hline
\end{tabular}

Table 3: $\quad$ Material parameters of load-bearing structure.

\begin{tabular}{|c|c|c|c|}
\hline & Brick & Sandstone & Arenaceus marl \\
\hline \hline$\rho\left[\mathrm{kg} / \mathrm{m}^{3}\right]$ & 1670 & 1809 & 1400 \\
\hline$\psi[\%]$ & 37.5 & 31.0 & 63.1 \\
\hline$c[\mathrm{~J} / \mathrm{kgK}]$ & 1202 & 850 & 837 \\
\hline$\mu[-]$ & 19.5 & 7.5 & 5.0 \\
\hline$\lambda_{\text {dry }}[\mathrm{W} / \mathrm{mK}]$ & 0.500 & 1.100 & 0.710 \\
\hline$\lambda_{\text {sat }}[\mathrm{W} / \mathrm{mK}]$ & 0.648 & 3.650 & 0.890 \\
\hline$\kappa\left[\mathrm{m}^{2} / \mathrm{s}\right]$ & $2.65 \cdot 10^{-7}$ & $2.5 \cdot 10^{-6}$ & $1.0 \cdot 10^{-8}$ \\
\hline$w_{\text {hyg }}\left[\mathrm{m}^{3} / \mathrm{m}^{3}\right]$ & 0.0480 & 0.00567 & 0.01 \\
\hline
\end{tabular}


All parameters were measured in Laboratory of Transport Processes of the Department of Materials Engineering and Chemistry, Faculty of Civil Engineering, Czech Technical University in Prague [12]. The adsorption and desorption isotherms of studied renovation plasters are shown in Figure 3.

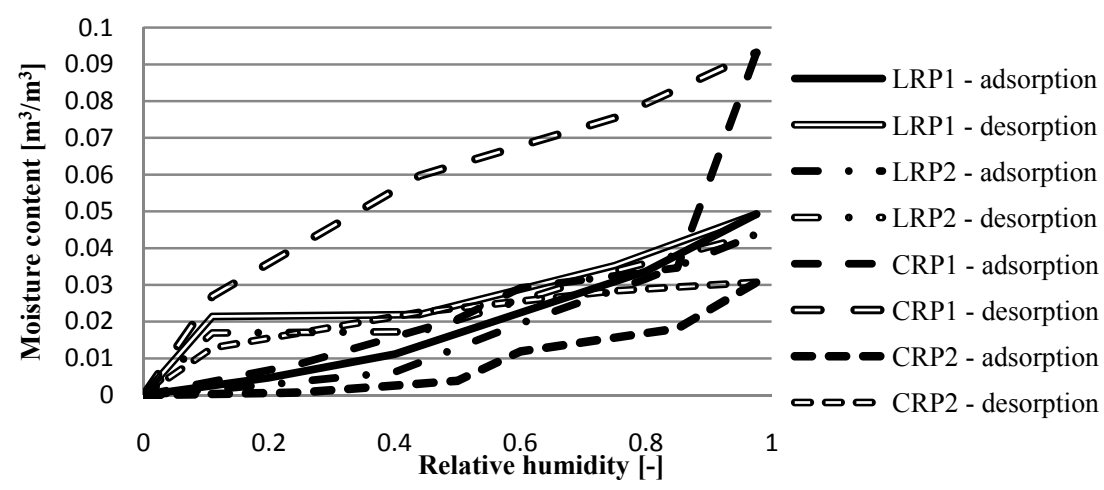

Figure 3: Adsorption and desorption isotherms of studied renovation plasters.

In Figure 4 we present the moisture diffusivity of the studied plasters which was obtained for absorption phase only. Contrary to the adsorption isotherms, where desorption curves can be obtained by common experimental techniques, the desorption curve of moisture diffusivity had to be set empirically as for its experimental determination no quite reliable techniques are available at present. Based on the results of experiments and computational analyses described in [6], it was estimated to be one order of magnitude lower than the absorption curve.

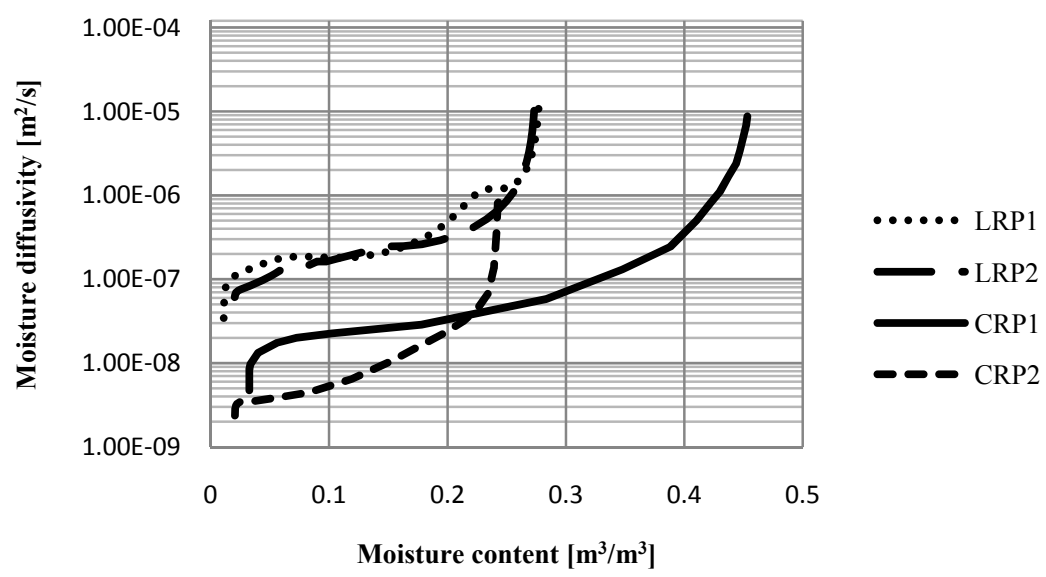

Figure 4: Moisture diffusivity of studied renovation plasters. 


\subsection{Computer simulation tool and mathematical model}

The computational analysis was performed using computer code HEMOT [7], which was developed at the Department of Materials Engineering and Chemistry, Faculty of Civil Engineering, Czech Technical University in Prague in order to support investigation of the coupled heat, moisture and salt transport in porous building materials. It enables simulation of thermal and hygric behaviour of constructive building details in 1-D or 2-D arrangement. The construction of the code is based on the application of general finite element computer simulation tool SIFEL (Simple Finite Elements) developed at Department of Mechanics, Faculty of Civil Engineering, Czech Technical University in Prague [8]. The Kunzel's diffusion model was used for description of coupled heat and moisture transport [9].

$$
\begin{gathered}
\frac{d \rho_{v}}{d \varphi} \frac{\partial \varphi}{\partial t}=\operatorname{div}\left[D_{\varphi} \operatorname{grad} \varphi+\delta_{p} \operatorname{grad}\left(\varphi p_{s}\right)\right] \\
\frac{d H}{d T} \frac{\partial T}{\partial t}=\operatorname{div}(\lambda \operatorname{grad} T)+L_{v} \operatorname{div}\left[\delta_{p} \operatorname{grad}\left(\varphi p_{s}\right)\right]
\end{gathered}
$$

where $\rho_{v}$ the partial density of moisture, $\varphi$ relative humidity, $\delta_{p}$ permeability of water vapour, $p_{s}$ partial pressure of saturated water vapour, $H$ enthalpy density, $L_{v}$ heat of evaporation, $\lambda$ thermal conductivity, $T$ temperature,

$$
D_{\varphi}=D_{w} \frac{d \rho_{v}}{d \varphi}
$$

is liquid moisture diffusivity coefficient, $D_{w}$ capillary transport coefficient.

Since the computational code involves the effect of hysteresis of moisture transport and storage parameters, which brings the computations nearer to reality, it was necessary to describe the path between adsorption and desorption phase. For that purpose an empirical procedure was chosen which follows Pedersen's hysteretic model [10],

$$
\xi=\frac{a_{d}\left(w_{p}-w_{a}\right)^{2} \xi_{d}+a_{a}\left(w_{p}-w_{d}\right)^{2} \xi_{a}}{\left(w_{d}-w_{a}\right)^{2}}
$$

where $w_{p}$ is the value of moisture content from previous calculation step, $w_{a}$ and $w_{d}$ are values of moisture content for adsorption and desorption cycles, $\xi_{a}$ and $\xi_{d}$ the values of tangent adsorption and desorption in the points $w_{a}$ and $w_{d}, a_{a}$ and $a_{d}$ the correction coefficients.

For describing the path between adsorption and desorption phase of moisture diffusivity, a modification was needed in order to express the hysteretic effect in more accurate way (see [11] for more details).

As boundary conditions in the exterior were used climatic data for Ostrava, Czech Republic, obtained using Meteonorm software, version 6.1, which is 
meteorological database and computer program for climatological calculations for every location on the globe.

\section{Results of computer simulation}

The results of computational simulations performed by HEMOT code with input parameters and boundary conditions presented in previous sections are presented below. All the computations were accomplished for five years. The results are given for the last year of the simulation.

\subsection{Load-bearing structure made of ceramic brick}

The differences between commercial plasters $\left(\mathrm{CRP}_{1}\right.$ and $\left.\mathrm{CRP}_{2}\right)$ and laboratory-prepared plasters $\left(\mathrm{LRP}_{1}\right.$ and $\left.\mathrm{LRP}_{2}\right)$ are quite significant. While commercial renovation plasters exhibit $4\left(\mathrm{CRP}_{1}\right)$, respectively $5\left(\mathrm{CRP}_{2}\right)$ freeze-thaw cycles, both laboratory-prepared renovation plasters showed only 1 freeze-thaw cycle.
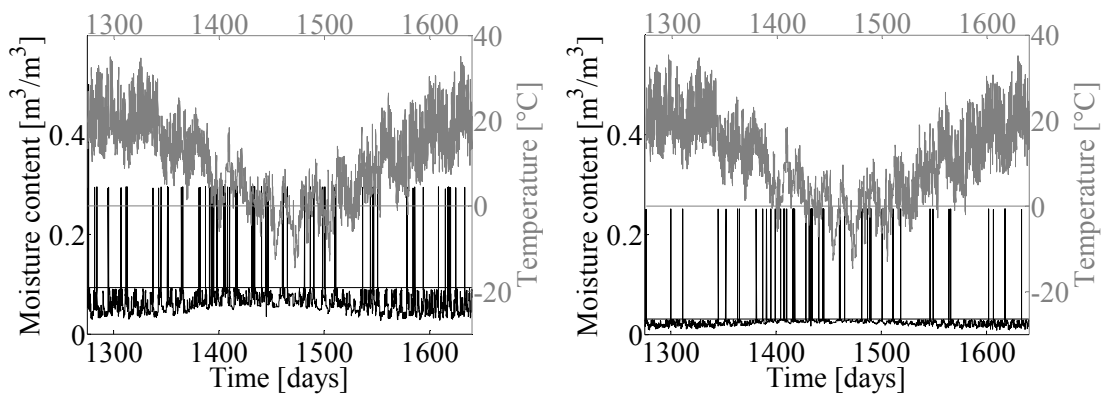

Figure 5: Time behaviour of temperature and moisture content in renovation plasters on load-bearing structure made of ceramic brick; $\mathrm{CRP}_{1}$ on the left, $\mathrm{CRP}_{2}$ on the right.
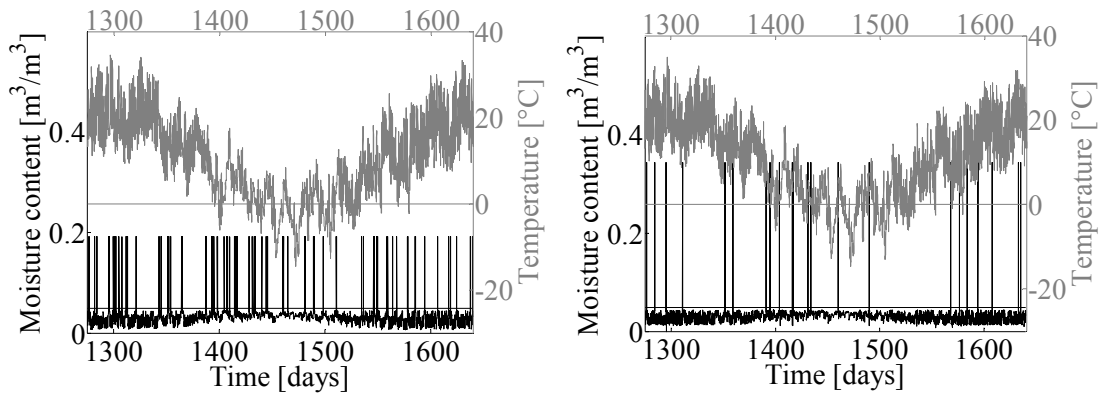

Figure 6: Time behaviour of temperature and moisture content in renovation plasters on load-bearing structure made of ceramic brick; $\mathrm{LRP}_{1}$ on the left, $\mathrm{LRP}_{2}$ on the right. 


\subsection{Load-bearing structure made of sandstone}

A similar situation as in brick masonry occurred in the sandstone masonry. Both laboratory-prepared plasters showed better results than commercial plasters. There occurred only 1 freeze-thaw cycle in $\mathrm{LCP}_{1}, 2$ freeze-thaw cycles in $\mathrm{LCP}_{2}, 3$ freeze-thaw cycles were discovered in $\mathrm{CRP}_{1}$ and 4 cycles in $\mathrm{CRP}_{2}$.
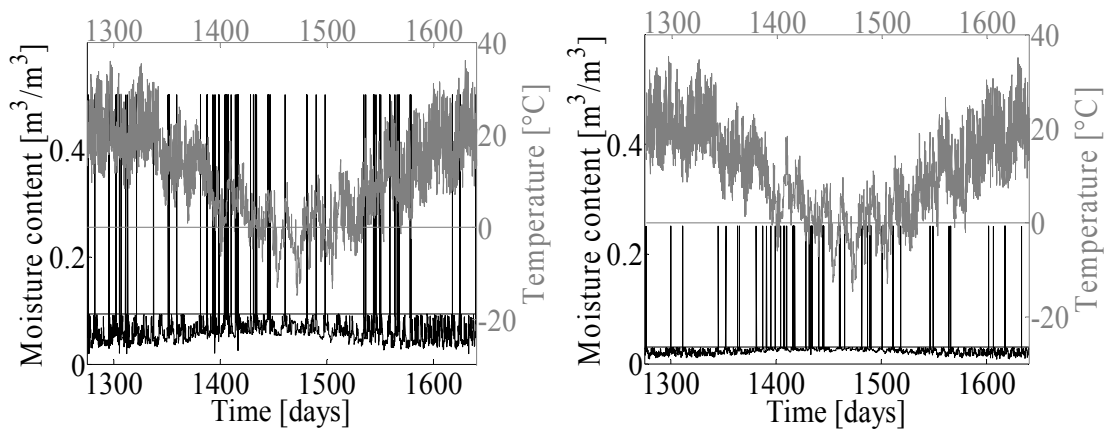

Figure 7: Time behaviour of temperature and moisture content in renovation plasters on load-bearing structure made of sandstone; $\mathrm{CRP}_{1}$ on the left, $\mathrm{CRP}_{2}$ on the right.
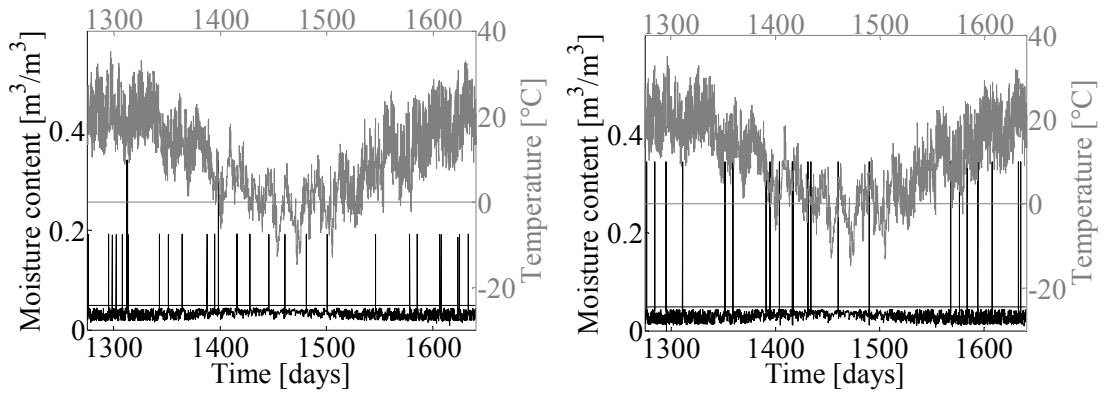

Figure 8: Time behaviour of temperature and moisture content in renovation plasters on load-bearing structure made of sandstone; $\mathrm{LRP}_{1}$ on the left, $\mathrm{LRP}_{2}$ on the right.

\subsection{Load-bearing structure made of arenaceous marl}

The worst results for all tested renovation renders were calculated for masonry made of arenaceous marl. Both laboratory-prepared renovation plasters showed 4 freeze-thaw cycles, commercial plasters exhibited one, respectively two cycles more (5 cycles for $\mathrm{CRP}_{1}$ and 6 cycles for $\mathrm{CRP}_{2}$ ). 

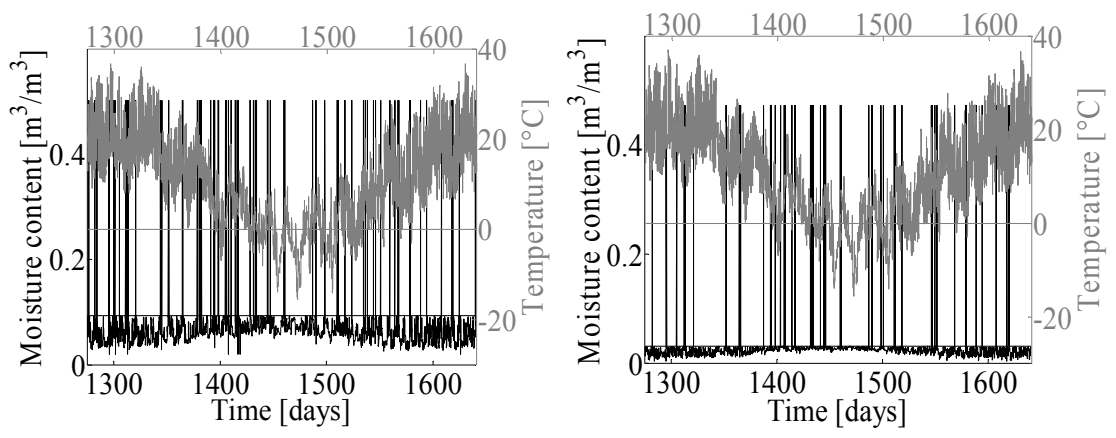

Figure 9: Time behaviour of temperature and moisture content in renovation plasters on load-bearing structure made of arenaceous marl; $\mathrm{CRP}_{1}$ on the left, $\mathrm{CRP}_{2}$ on the right.
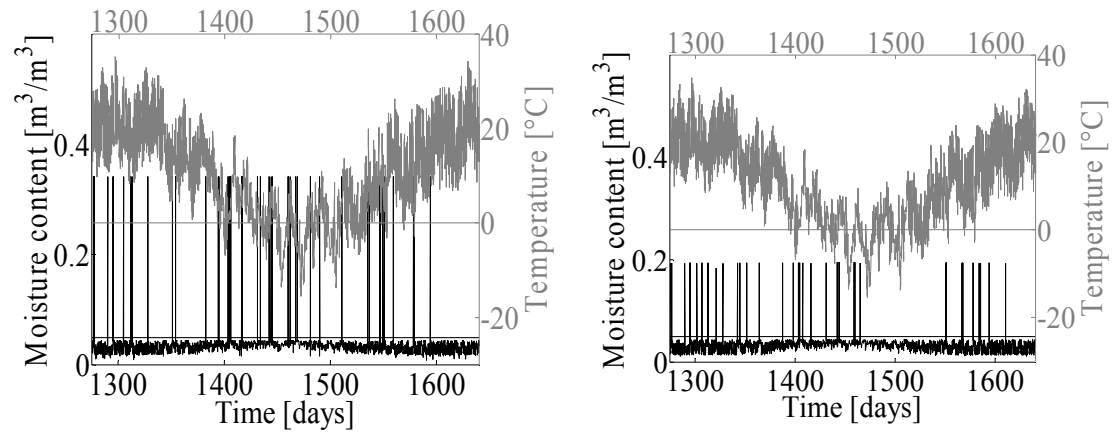

Figure 10: Time behaviour of temperature and moisture content in renovation plasters on load-bearing structure made of arenaceous marl; $\mathrm{CRP}_{1}$ on the left, $\mathrm{CRP}_{2}$ on the right.

\section{Discussion}

In this paper, we assumed phase changes of water as the only factor affecting the service life of innovative plasters. In reality, there are more factors playing the key role in damage of surface layers of renovation renders, like salt transport, microbiological damage, acid rains etc. On the other hand, this simplification based on separation of the particular effect of damage (frost resistance) from variety of other effects can provide valuable information indeed.

All performed computations proved, that freeze-thaw cycles may occur in surface layers of renovation renders, even when reference year is taken into account. In Table 4 there are summarized all results calculated using computer simulations. 
Table 4: $\quad$ Summary of freeze/thaw cycles appearance during a reference year.

\begin{tabular}{|c|c|c|c|c|}
\hline & $\mathrm{LRP}_{1}$ & $\mathrm{LRP}_{2}$ & $\mathrm{CRP}_{1}$ & $\mathrm{CRP}_{2}$ \\
\hline \hline Ceramic brick & 1 & 1 & 4 & 5 \\
\hline Sandstone & 1 & 2 & 3 & 4 \\
\hline Arenaceous marl & 4 & 4 & 5 & 6 \\
\hline
\end{tabular}

Best results were achieved for $\mathrm{LRP}_{1}$ but all investigated plasters fared well. The most significant differences between studied plasters were discovered on brick masonry. The other types of masonry resulted in very similar appearance of freeze-thaw cycles.

Taking into account the frost resistance of each renovation render (Table 1), we can predict its service life. From this point of view it may be recommended to use $\mathrm{LRP}_{1}$ or $\mathrm{LRP}_{2}$ for brick masonry, $\mathrm{LRP}_{1}$ or $\mathrm{CRP}_{1}$ for sandstone masonry and $\mathrm{CRP}_{1}$ for masonry made of arenaceous marl. An interesting finding is that both commercially available products $\mathrm{CRP}_{1}$ and $\mathrm{CRP}_{2}$ sold for a similar price showed very different results. Average service life of $\mathrm{CRP}_{1}$ was approximately two times higher than $\mathrm{CRP}_{2}$ regarding the frost resistance.

\section{Conclusions}

The computational results presented in this paper dealing with hygrothermal performance of innovative renovation renders showed that proper choice of materials for renovation, with respect to material of load-bearing structure, could significantly extend service life of a renovated building envelope. In general, the best results were achieved for brick masonry, whereas the worst results were obtained for masonry made of arenaceous marl. It is important to say, that durability of renovation renders is not only affected by cyclic freezing and wetting. Crucial contribution to reducing of service life of all types of renovation renders comes from salt accumulation and crystallization due to their high open porosity. Therefore, in future work the mathematical model should be extended by involving salt transport as well.

\section{Acknowledgement}

This research has been supported by the Czech Science Foundation, under grant No 103/09/0780.

\section{References}

[1] Kočí, J., Kočí, V., Maděra, J., Rovnaníková, P., Černý, R., Computational analysis of hygrothermal performance of renovation renders. In: Advanced Computational Methods and Experiments in Heat Transfer XI. WIT Press: Southampton, pp. 267-277, 2010. 
[2] Maděra, J. - Kočí, V. - Vejmelková, E. - Černý, R. - Rovnaníková, P. - et al. Influence of material characteristics of concrete and thermal insulation on the service life of exterior renders. In: Fourteenth International Conference on Computational Methods and Experimental Measurements, Algarve, Portugal. WIT Press: Southampton, pp. 13-23, 2009.

[3] Lu, G., Lu, G.Q., Xiao, Z.M., Mechanical properties of porous materials. Journal of Porous Materials, 6, pp. 359 -368, 1999.

[4] Larbi, J.A. Microscopy applied to the diagnosis of the deterioration of brick masonry. Construction and Building Materials, 18, pp. 299-307, 2004.

[5] Mendes, N., Philippi, P.C. A method for predicting heat and moisture transfer through multilayered walls based on temperature and moisture content gradients. International Journal of Heat and Mass Transfer, 48, pp. 37-51, 2005.

[6] Pel L., Černý R., Pavlík Z. Moisture and Ion Transport. WP5 2-Years Report of the EU 6th Program Project SSPI-CT-2003-501571. TU Eindhoven, Eindhoven, 2006.

[7] Černý R., Complex System of Methods for Directed Design and Assessment of Functional Properties of Building Materials: Assessment and Synthesis of Analytical Data and Construction of the System. CTU: Prague, pp. $192-201.2010$.

[8] Kruis J., Koudelka T., Krejčí T. Efficient computer implementation of coupled hydro-thermo-mechanical analysis. Mathematics and Computers in Simulation, doi:10.1016/j.matcom.2008.11.010

[9] Künzel, H. M., Simultaneous Heat and Moisture Transport in Building Components, PhD Thesis, IRB Verlag Stuttgart, 1995.

[10] Pedersen, C. R., Combined Heat and Moisture Transfer in Building Constructions, $\mathrm{PhD}$ Thesis, Report 214. Thermal Insulation Laboratory, TU Denmark, 1990.

[11] Černý, R., Maděra, J., Kočí, J., Vejmelková, E. Heat and moisture transport in porous materials involving cyclic wetting and drying. Fourteenth International Conference on Computational Methods and Experimental Measurements, Algarve, Portugal. WIT Press: Southampton, pp. 3-12, 2009.

[12] Vejmelková, E., Keppert, M., Máca, P., Černý, R. Mechanical, hygric and thermal properties of innovative renovation renders. In: 12th International Conference on Structural Repairs and Maintenance of Heritage Architecture, Chianciano Terme, Italy. WIT Press: Southampton 